\title{
SOBRE O PADRÃO DE CIRCULAÇÃO DO ESTUÁRIO SANTISTA
}

\author{
WALDIR LOPES PONÇANO* E ANTONIO FERNANDO GIMENEZ**
}

\begin{abstract}
Studies on salinity and supended matter allowed to attribute the circulation pattern of port channel, main branch of the Santos estuary to the two-lawyer flow with vertical mixing type; the São Vicente Channel belongs almost entirely to the vertically homogeneous type, with some slight stratification in its inner part. The collected samples are representative of high water and low water, both for spring tides, under summer conditions of maximum fluvial đischarge.
\end{abstract}

INTRODUÇÃO $O$ estuário santista situa-se em unidade fisiográfica bem definida, conhecida como Baixada Santista, objeto de numerosos estudos, entre os quais a extensa monografia organizada por Azevedo (1965). Este estuário, em que se encontra implantado o Porto de Santos, mereceu estudos parciais realizados por pesquisadores do Laboratório de Hidráulica da Escola Politécnica da Universidade de São Paulo/Departamento de Águas e Energia Elétrica (EPUSP/DAEE 1966). A partir de 1973, mediante diversas campanhas, desenvolvemos também alguma pesquisa nessa área, parcialmente publicada no que se refere aos sedimentos de superfície de fundo (Fúlfaro \& Ponçano 1976, Fúlfaro et al. 1976, Ponçano \& Fúlfaro 1976). Este trabalho visa apresentar os principais resultados obtidos no estudo da salinidade das águas e sedimentos em suspensão. Estes dois fatores já foram previamente examinados (EPUSP/DAEE 1966) visando o primeiro, caracterizar a importância da floculação no processo de formação de vasas na faixa portuária e, o segundo, determinar a importância dos sólidos em suspensão no assoreamento dessa mesma faixa. Para tanto, foram coletadas amostras de água em seções dos rios Cascalho, Casqueiro, Jurubatuba, Diana-Sandi e Canal de Bertioga, em diversas profundidades. A amostragem para material em suspensão estendeu-se de 19 de junho de 1964 a 20 de maio de 1966 , enquanto as salinidades e as velocidades de correntes foram medidas de 18 a 20 de maio de 1966.

Os resultados obtidos mostraram valores de salinidade decrescente em direção ao interior do estuário, que variaram de 30.000 a 22.900 ppm de sais.

Por outro lado, sempre segundo EPUSP/DAEE (1966), a variação entre as concentrações de sólidos em suspensão na enchente e na vazante era mínima, e a inversão de corrente invalidaria cálculos buscando estabelecer predomínio de transporte num ou em outro sentido; apenas no Canal de Bertioga e na embocadura do Diana-Sandi (Fig. 1) haveria dominância de material em suspensão durante as vazantes, o que contribuiria para assoreamento dessas áreas. Nesses dois caos, ambos para situação de verão, as concentrações de material em suspensão variaram entre 10 e $240 \mathrm{mg} / 1$ enquanto nas outras seções variaram entre 5 e $50 \mathrm{mg} / \mathrm{l}$, tanto para situações de verão como de inverno. $O$ equilíbrio morfológico regional, associado às baixas concentrações de material em suspensão, explicaria as baixas taxas de assoreamento no canal do porto; a própria floculação, que teria lugar nas partes mais altas do estuário, fixaria parte da descarga sólida e propiciaria o crescimento dos manguezais. A proveniência dos sólidos em suspensão seria continental e a circulação estuarina, do tipo cunha salina.

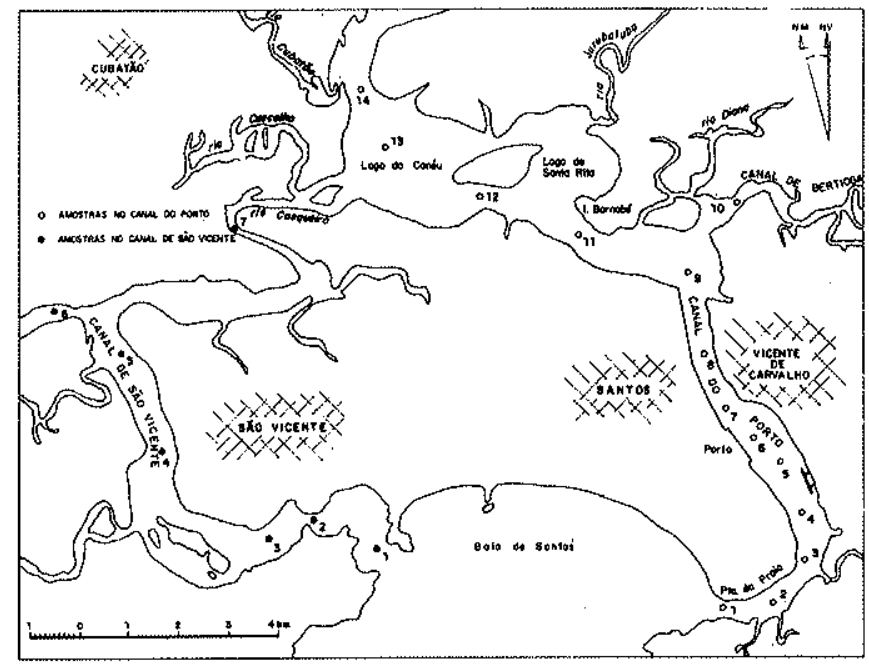

Figura l - Localização das estações de amostragem

Procuramos aqui retomar o assunto, porém com abordagem distinta, essencialmente voltada para a definição do modelo de circulação estuarina.

A área estudada situa-se em região de clima tropical subquente, superúmido (Nimer 1977), caracterizado por pluviosidade anual de 2.000 a $2.500 \mathrm{~mm}$, com forte concentração (média de $791 \mathrm{~mm}$ ) nos meses de verão (janeiro a março) e diminuindo sensivelmente (média de $322,6 \mathrm{~mm}$ ) nos meses de inverno (junho a agosto), segundo observações do periodo 1944-1962 (EPUSP/DAEE 1966). As vazões dos cursos d'água, que drenam para o estuário, respondem a esse regime, conforme mostram os dados entre 1966 e 1970 para o Rio Cubatão (DAEE 1974). O estuário santista apresenta amplitudes máximas de maré em torno de 1,3 m.

MATERIAIS E MÉTODOS A coleta de amostras foi efetuada com barco de alumínio, de fundo chato, especialmente adaptado para esta finalidade e equipado com guincho e roldanas, e com motor de popa de $50 \mathrm{HP}$. As amostras de água foram coletadas com garrafas de Van Door de 3 litros de capacidade, a $1 \mathrm{~m}$ da superfície da água $(T)$, a $1 \mathrm{~m}$

* Instituto de Pesquisas Tecnológicas do Estado de São Paulo - IPT-DMGA. Cx. Postal 7141, CEP 01000, São Paulo, SP, Brasil; Instituto de Geociências e Ciências Exatas, CEP 13500, Rio Claro, SP, Brasil.

**Instituto de Pesquisas Tecnológicas do Estado de São Paulo IPT DMGA. Cx. Postal 7141, CEP 0100, São Paulo, SP, Brasil 
do fundo $(B)$ e a profundidade intermediária $(M)$ nas estações mostradas na figura 1.

As amostras foram coletadas em situações de preamar e baixa-mar, em marés de sizígia de 21 e 22 de janeiro de 1985, em duas seções longitudinais: uma, desde a barra do porto até a região dos largos, com 14 estaçסes de amostra* gem e, outra, abrangendo o Canal de São Vicente e sua ligação com os largos, com sete estações (Fig. 1). A operação de coleta acompanhou a estofa da maré e se realizou entre 40 minutos antes e 40 minutos após as horas de referência de preamar e baixa-mar referidas na tábua de marés.

Os teores de material em suspensão foram determinados pela filtragem a vácuo de 1 litro de água em filtro Sartorius de $47 \mathrm{~mm}$ de diâmetro e $0,45 \mu$ de porosidade, com pesagem de precisão $\pm 10^{-4} \mathrm{~g}$.

As salinidades foram determinadas em equivalentes de $\mathrm{NaCl}$ a $25 \circ \mathrm{C}$ (em ppm) a partir de resistividades obtidas em condutivímetro CM2A, Toa Electronics Ltd.

Os dados hidrológicos disponiveis para anos prévios (DAEE 1974) indicam que a amostragem se processou em situação de verão, estimando-se que o padrão resultante reflita condiç̧̃es de máxima contribuição fluvial.

RESULTADOS OBTIDOS Salinidade Os valores de salinidade estão apresentados nas tabelas $1 \mathrm{e} 2$. Com eles preparamos as seções de preamar e baixa-mar dos canais do porto e de São Vicente até a região dos largos, apresentadas nas figuras 2 e 3 .

Tabela 1 - Valores de salinidade no canal porto e na região dos largos, em situações de preamar e baixa mar

\begin{tabular}{|c|c|c|c|c|c|c|c|}
\hline \multicolumn{4}{|c|}{ Preamar } & \multicolumn{4}{|c|}{ Baixa-Mar } \\
\hline Amostra & \begin{tabular}{|c} 
Salinidade \\
(ppm de NaCl)
\end{tabular} & Amostra & $\begin{array}{c}\text { Satintidade } \\
\text { (ppm de } \mathrm{NaCl} \text { ) }\end{array}$ & Amostra & $\begin{array}{c}\text { Salinidade } \\
\text { (ppm de } \mathrm{NaCl} \text { ) }\end{array}$ & Amostrá & $\begin{array}{c}\text { Salitildade } \\
\text { (ppm de } \mathrm{NaCl}\end{array}$ \\
\hline IT & 23.000 & $8 \mathrm{~T}$ & 18.000 & 17 & 24,000 & $8 \mathrm{~T}$ & 17.500 \\
\hline $1 \mathrm{M}$ & 29.000 & $8 M$ & 28.000 & $1 \mathrm{M}$ & 28.000 & $8 \mathrm{M}$ & 27.000 \\
\hline IB & 29.500 & $8 B$ & 29.500 & $1 \mathrm{~B}$ & 29.000 & $8 B$ & 28.000 \\
\hline $2 T$ & 23.000 & 97 & 17.500 & 27 & 20.000 & $9 \mathrm{~T}^{\circ}$ & 16.000 \\
\hline $2 M$ & 27,000 & $9 \mathrm{M}$ & 28.000 & $2 \mathrm{M}$ & 27.0 & $9 \mathrm{M}$ & 28.000 \\
\hline 28 & 28.000 & 98 & 29.000 & $2 \mathrm{~B}$ & 28.000 & $9 \mathrm{~B}$ & 28.000 \\
\hline & $19.5 \theta$ & $10 \mathrm{~T}$ & 14.000 & $3 \mathrm{~T}$ & 19.000 & $10 \mathrm{~T}$ & 15.500 \\
\hline $3 \mathrm{M}$ & 29.000 & $10 \mathrm{M}$ & 230 & $3 M$ & 29. & $10 \mathrm{M}$ & 16.000 \\
\hline $3 \mathrm{~B}$ & 29.50 & $10 \mathrm{~B}$ & 24.000 & $3 B$ & 29.000 & $\mathrm{IOB}$ & 18.000 \\
\hline $4 \mathrm{~T}$ & 20.500 & 117 & 17.000 & $4 T$ & 19.500 & IIT & $\$ 4.000$ \\
\hline $4 N$ & 28.000 & $11 \mathrm{M}$ & 27.000 & $4 M$ & 26. & IIM & 27.000 \\
\hline $4 B$ & 29 & 1:B & 28. & $4 B$ & 29. & IIB & 27.500 \\
\hline ST & 22.50 & $12 \mathrm{~T}$ & 14.50 & $5 T$ & 18. & $12 \mathrm{~T}$ & 12.000 \\
\hline$S M$ & 27.000 & $12 \mathrm{M}$ & 27.000 & $S M$ & 27.000 & $12 \mathrm{M}$ & 27.500 \\
\hline $5 B$ & 29.000 & $12 \mathrm{~B}$ & 28.000 & $5 \mathrm{~B}$ & & $12 \mathrm{~B}$ & 28.000 \\
\hline $6 \mathrm{~T}$ & & & & $6 T$ & & I3T & 10.000 \\
\hline $6 \mathrm{M}$ & 28.000 & $13 \mathrm{M}$ & 27. & $6 M$ & 27.500 & $13 \mathrm{M}$ & 24.500 \\
\hline 6B & 29.000 & 1313 & 27.000 & $6 \mathrm{~B}$ & 29.000 & $13 B$ & 27.000 \\
\hline $7 T$ & 19.000 & $14 \mathrm{~T}$ & 14.500 & $7 \mathrm{~T}$ & 18.000 & $14 \mathrm{~T}$ & 10.500 \\
\hline $7 \mathrm{M}$ & 29.0 & $14 \mathrm{M}$ & 27. & $7 \mathrm{M}$ & & $14 M$ & 23.000 \\
\hline $7 B$ & 29.500 & $14 B$ & 27.500 & 73 & 29.000 & $14 B$ & 27.500 \\
\hline
\end{tabular}

$\mathrm{T}$ - amostra coletada a $1 \mathrm{~m}$ da superfície da água

$\mathrm{M}$ - amostra coletada a meia profundidađe da seção

$\mathrm{B}$ - amostra coletada a $1 \mathrm{~m}$ do fundo

Ambas as seções do canal do porto até a região dos largos mostram acentuada estratificação ao longo de pouco mais de $16 \mathrm{~km}$ investigados (Fig. 2). Na situação de preamar, o estrato inferior apresenta menos de $10 \%$ de variação máxima de salinidade, desde a barra do estuário até o Largo do Canéu; o gradiente de salinidade sofre brusca variação na curva de isovalor de $28.000 \mathrm{ppp}$ de $\mathrm{NaCl}$.

Na baixa-mar, a situação é semelhante, também balizada pela curva de isovalor de $28.000 \mathrm{ppm} \mathrm{de} \mathrm{NaCl}$. Entretanto a montante da estação 11, no Largo do Canéu, a camada inferior tende a desaparecer e seu valor de salinidade se aproxima do da camada superior. Ainda a montante da seção 5 , observa-se ligeira diminuição de salinidade da camada
Tabela 2 - Valores de salinidade no Canal de São Vicente em situações de preamar e baixa-mar

\begin{tabular}{|c|c|c|c|}
\hline Amostra & $\begin{array}{c}\text { Salinidade } \\
\text { (ppm de } \mathrm{NaCl} \text { ) }\end{array}$ & Amostra & $\begin{array}{c}\text { Salinidade } \\
\text { (ppm de } \mathrm{NaCl} \text { ) }\end{array}$ \\
\hline $1 \mathrm{~T}$ & 29.000 & $1 \mathrm{~T}$ & - \\
\hline $1 \mathrm{M}$ & 30.000 & $1 \mathrm{M}$ & - \\
\hline $1 B$ & 30.000 & $1 \mathrm{~B}$ & - \\
\hline $2 \mathrm{~T}$ & 26.500 & $2 T$ & 18.000 \\
\hline $2 \mathrm{M}$ & 29.000 & $2 \mathrm{M}$ & 23.000 \\
\hline $2 B$ & 30.000 & $2 B$ & 27.000 \\
\hline $3 \mathrm{~T}$ & 24.000 & $3 \mathrm{~T}$ & 16.000 \\
\hline $3 M$ & 27.000 & $3 M$ & 19.000 \\
\hline $3 B$ & 26.500 & $3 B$ & 18.000 \\
\hline $4 \mathrm{~T}$ & 21.000 & $4 \mathrm{~T}$ & 13.000 \\
\hline $4 \mathrm{M}$ & 22.000 & $4 \mathrm{M}$ & 14.000 \\
\hline $4 B$ & 23.000 & $4 B$ & 15.500 \\
\hline $5 \mathrm{~T}$ & 15.500 & $5 T$ & 8.600 \\
\hline $5 \mathrm{M}$ & - & $5 \mathrm{M}$ & - \\
\hline $5 B$ & 19.000 & $5 B$ & 12.000 \\
\hline $6 \mathrm{~T}$ & 14.100 & $6 \mathrm{~T}$ & 6.300 \\
\hline $6 \mathrm{M}$ & 15.500 & $6 \mathrm{M}$ & 11.000 \\
\hline $6 \mathrm{~B}$ & 15.100 & $6 \mathrm{~B}$ & 12.500 \\
\hline $7 \mathrm{~T}$ & 8.900 & $7 \mathrm{~T}$ & 12.300 \\
\hline $7 \mathrm{M}$ & 19.000 & $7 \hat{\mathrm{M}}$ & 13.000 \\
\hline $7 \mathrm{~B}$ & - & $7 \mathrm{~B}$ & 14.100 \\
\hline
\end{tabular}

$\mathrm{T}$ - amostra coletada a $1 \mathrm{~m}$ da superfície dă água.

M - amostra coletada a meia profundidade da seção.

$\mathrm{B}$ - amostra coletada a $1 \mathrm{~m}$ do fundo.
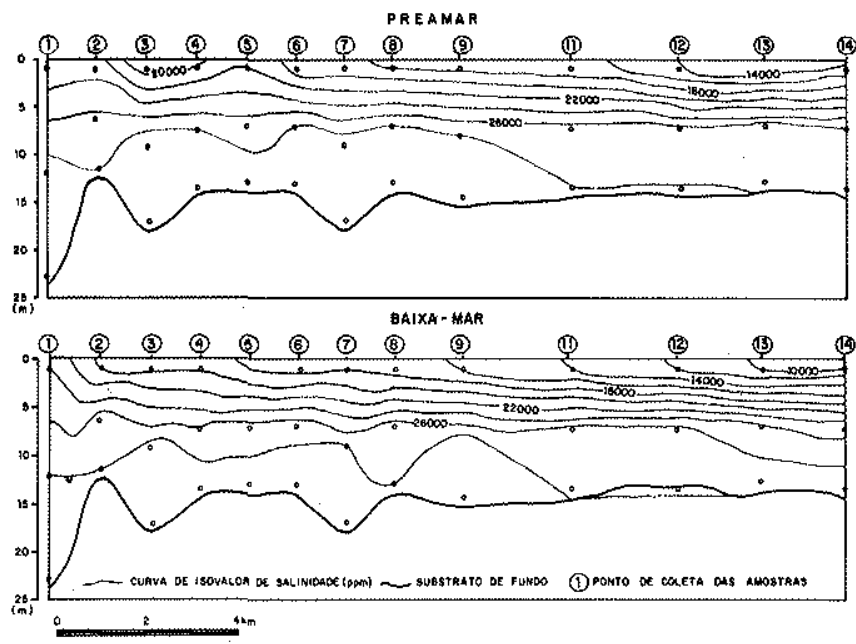

Figura 2 - Distribuição de salinidades do canal do porto $e$ na regiäo dos largos, em preamar e em baixa-mar

superior comparativamente à situação de preamar.

Para as duas situações, preamar e baixa-mar, pode-se constatar mistura de água salgada e água doce, pouco pro. nunciada no estrato inferior e maior no superior. Para o estrato superior, em nenhum dos dois casos se configura um gradiente mais acentuado, definido por alguma variação brusca nas curvas.

Bem diversa é a situação ao longo do Canal de São Vicente, em que as salinidades são nitidamente maiores na preamar que na baixa-mar (Fig. 3). Em ambas as situações, alguma estratificação, mais nítida na preamar, começa a se esboçar apenas a montante da estação 5 , ou seja, no Largo da Pompeba e em sua ligação com o Largo do Canéu. Nos demais, os valores de salinidade aumentam progressivamente de jusante para montante e caracterizam uma mistura mais efetiva de águas doce e salgada. 


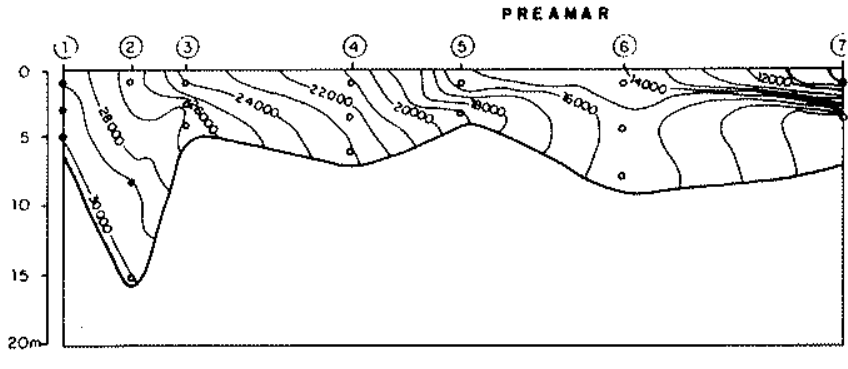

(3)

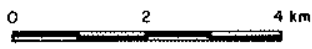

BAIXA-MAR

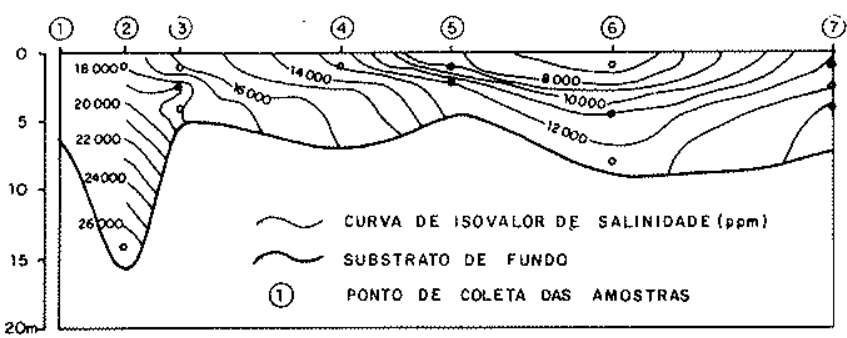

Figura 3 - Distribuição de salinidades no Canal de São Vicente em preamar e em baixa-mar

Material em suspensão Os teores de material em suspensão só foram obtidos para a seção ao longo do canal porto e da região dos largos e os valores são apresentados na tabela 3.

Provavelmente, a constatação mais notável que se pode fazer, de início, refere-se aos teores de sólidos em suspensão, que se mantêm, em sua maior parte, na mesma faixa dos valores obtidos entre 1964 e 1966 (EPUSP/DAEE 1966). Este fato vem de encontro a observações feitas anteriormente (EPUSP/DAEE 1966, Fúlfaro \& Ponçano 1976) no sentido de que o sistema de circulação de sedimentos no estuário santista é bastante equilibrado. Assim, não obstante a intensificação dos processos de erosão nas encostas da Serra do Mar, decorrentes da implantação de obras viárias, da exploração de materiais de construção e da degradação da cobertura vegetal por poluentes, não parece ter havido um incremento permanente nos teores do material transportado em suspensão.

A distribuição do material em suspensão em situações de preamar e baixa-mar pode ser visualizada na figura 4 .

Nas duas situações, nota-se que as maiores concentrações de material em suspensão mostram boa coincidência com a disposição das porções de água salgada. Este padrão sugere que o aporte de sólidos em suspensão de origem continental é menor que o de origem marinha, como, aliás, se verifica na maior parte dos estuários (Postma 1967).

CIRCULAÇÃO ESTUARINA A literatura indica que os dois parâmetros mais característicos da circulação estuarina são as distribuições de salinidades e de velocidades de corrente (cf. Bowden 1967). Entre os quatro tipos básicos de circulação estuarina apresentados por Bowden (1967) cunha salina, estratificado com aporte (two-layer flow with entrainement), estratificado com mistura vertical (two layer flow with vertical mixing/partially mixed estuaries) e verticalmente homogêneo -, é o terceiro que podemos considerar como representativo do trecho do estuário santista na seção canal do porto largo do Canéu, se levarmos em conta a distribuição de salinidades mostrada na figura 2 . Neste tipo de estuário, não há nítida separação entre águas doce e
Tabela 3 - Teores de material em suspensão no canal do porto e na região dos largos, em situações de preamar $e$ baixa-mar

\begin{tabular}{|c|c|c|c|}
\hline \multicolumn{2}{|c|}{ Premar } & \multicolumn{2}{|c|}{ Baixa-Mar } \\
\hline Amostra & $\begin{array}{l}\text { Material em } \\
\text { suspensão } \\
(\mathrm{mg} / \mathrm{l})\end{array}$ & Amostra & $\begin{array}{l}\text { Material em } \\
\text { suspensão } \\
\text { (mg/l) }\end{array}$ \\
\hline $1 T$ & 9,1 & $1 \mathrm{~T}$ & 4,6 \\
\hline $1 \mathrm{M}$ & 10,6 & $1 \mathrm{M}$ & 19,5 \\
\hline $1 \mathrm{~B}$ & 18,0 & $1 \mathrm{~B}$ & 59,0 \\
\hline $2 \mathrm{~T}$ & 11,5 & $2 T$ & 7,2 \\
\hline $2 \mathrm{M}$ & 11,2 & $2 \mathrm{M}$ & 6,0 \\
\hline $2 \mathrm{~B}$ & 32,9 & $2 B$ & 112,8 \\
\hline $3 \mathrm{~T}$ & 7,9 & $3 \mathrm{~T}$ & 6,1 \\
\hline $3 \mathrm{M}$ & 22,5 & $3 \mathrm{M}$ & 6,4 \\
\hline $3 B$ & 53,8 & 3B & 13,6 \\
\hline $4 \mathrm{~T}$ & 3,0 & $4 \mathrm{~T}$ & 5,1 \\
\hline $4 \mathrm{M}$ & 12,8 & $4 \mathrm{M}$ & 8,1 \\
\hline $4 \mathrm{~B}$ & 38,8 & $4 \mathrm{~B}$ & 17,8 \\
\hline $5 \mathrm{~T}$ & 6,2 & $5 \mathrm{~T}$ & 7,5 \\
\hline $5 \mathrm{M}$ & 10,0 & $5 \mathrm{M}$ & 12,6 \\
\hline $5 B$ & 24,4 & $5 \mathrm{~B}$ & 23,2 \\
\hline $6 \mathrm{~T}$ & 7,3 & $6 \mathrm{~T}$ & 8,5 \\
\hline $6 \mathrm{M}$ & 11,2 & $6 \mathrm{M}$ & 12,7 \\
\hline $6 B$ & 19,1 & $6 \mathrm{~B}$ & 12,0 \\
\hline $7 \mathrm{~T}$ & 3,4 & $7 \mathrm{~T}$ & 10,5 \\
\hline $7 \mathrm{M}$ & 14,1 & $7 \mathrm{M}$ & 10,1 \\
\hline $7 \mathrm{~B}$ & 30,2 & $7 \mathrm{~B}$ & 29,1 \\
\hline $8 \pi$ & 7,9 & $8 \mathrm{~T}$ & 8,9 \\
\hline $8 \mathrm{M}$ & 7,3 & $8 \mathrm{M}$ & 12,5 \\
\hline $8 \mathrm{~B}$ & 18,0 & $8 B$ & 50,0 \\
\hline $9 \mathrm{~T}$ & 4,7 & $9 \mathrm{~T}$ & 7,5 \\
\hline $9 \mathrm{M}$ & 16,3 & $9 \mathrm{M}$ & 16,6 \\
\hline $9 \mathrm{~B}$ & 24,6 & $9 \mathrm{~B}$ & 21,7 \\
\hline $10 \mathrm{~T}$ & 8,0 & $10 \mathrm{~T}$ & 7,1 \\
\hline $10 \mathrm{M}$ & 11,0 & $10 \mathrm{M}$ & 10,7 \\
\hline $10 \mathrm{~B}$ & 12,7 & $10 \mathrm{~B}$ & 15,6 \\
\hline $11 \mathrm{~T}$ & 7,1 & $11 \mathrm{~T}$ & 8,9 \\
\hline $11 \mathrm{M}$ & 13,9 & $11 \mathrm{M}$ & 11,4 \\
\hline $11 \mathrm{~B}$ & 22,1 & $11 B$ & 10,7 \\
\hline $12 \mathrm{~T}$ & 6,6 & $12 T$ & 8,2 \\
\hline $12 \mathrm{M}$ & 13,9 & $12 \mathrm{M}$ & 9,1 \\
\hline $12 B$ & 20,3 & $12 \mathrm{~B}$ & 9,3 \\
\hline $13 \mathrm{~T}$ & 8,1 & $13 \mathrm{~T}$ & 9,3 \\
\hline $13 \mathrm{M}$ & 14,8 & $13 \mathrm{M}$ & 7,9 \\
\hline $13 \mathrm{~B}$ & 22,9 & $13 B$ & 8,1 \\
\hline $14 \mathrm{~T}$ & 6,4 & $14 \mathrm{~T}$ & 8,1 \\
\hline $14 \mathrm{M}$ & 11,7 & $14 \mathrm{M}$ & 5,9 \\
\hline $14 B$ & 8,0 & $14 \mathrm{~B}$ & 5,6 \\
\hline
\end{tabular}

$\mathrm{T}$ - amostra coletada a $1 \mathrm{~m}$ da superfície da água

$M$ - amostra coletada a meia profundidade da seção

B - amostra coletada a $1 \mathrm{~m}$ do fundo
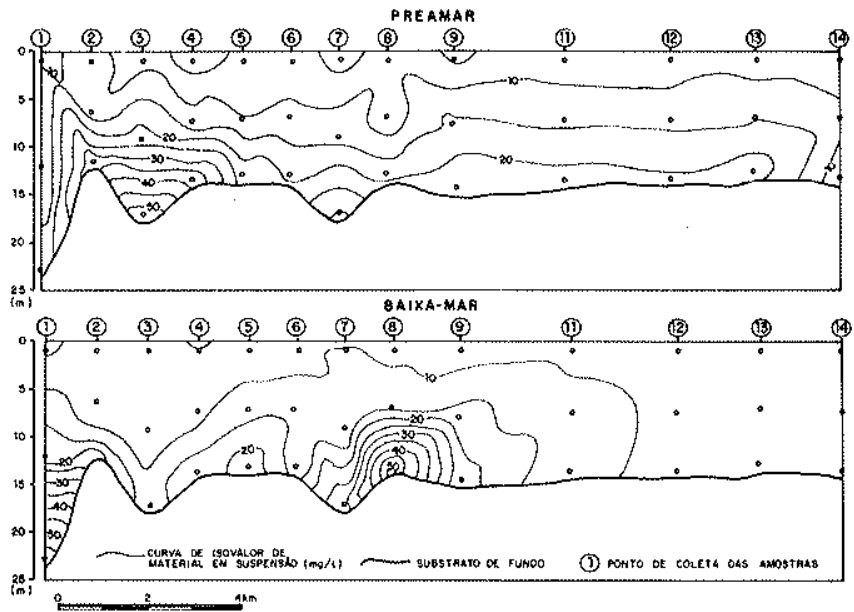

Figura 4 - Distribuição do material em suspensäo no canal do porto e na região dos largos, em preamar e em baixa-mar 
salgada, e, sim, um aumento contínuo de salinidade em direção ao fundo.

Nos estuários estratificados com mistura vertical, a distribuição de velocidades mostra um padrão em que a camada inferior se movimenta para montante; o ponto de inflexão, com velocidades próximas de zero, situa-se da metade para - terço superior da seção, após o que a camada superior passa a se movimentar para jusante (Bowden 1967). No sentido de ilustrar o esquema de circulação acima mencionado, recorremos a duas séries de medições de velocidades de corrente e salinidades apresentadas no trabalho da EPUSP/DAEE. (1966) realizadas na Ponta da Praia (barra do canal do porto) e à altura da liha Barnabé. Foram selecionadas as horas de medidas mais próximas das situações de baixa-mar e preamar de marés de sizígia ocorridas entre 19 e 21 de maio de 1966. A figura 5 mostra os perfis de velocidades e salinidades nas seções escolhidas.

Os dados da figura 5 vêm de encontro ao modelo de circulação aqui cogitado, embora não se possa projetá-los diretamente para as condições da campanha de 21 e 22 de janeiro de 1985. Assim, pelos dados obtidos pela EPUSP/DAEE em 1966, verifica-se que tanto o maior gradiente de salinidades se encontra na porção do terço superior dos perfis, como a zona de velocidades próximas a zero encontra-se aí localizada. Essas situações podem ser claramente observadas tanto para preamar como para baixa-mar (Fig. 5) e são características dos estuários estratificados com mistura vertical (Bowden 1967).

No caso da seção Canal de São Vicente-Largos, não dispomos de medidas de velocidade de corrente. Entretanto, neste caso, não há dúvida de que, na maior parte de seção, o gradiente de salinidade é quase horizontal, o que caracteriza então uma circulação do tipo verticalmente homogênea. Conforme já notáramos, na região dos largos, há uma tendência à maior estratificação, tanto em preamar como em baixa-mar (Figs. 4 e 5 ).

Procuramos a seguir verificar quais as implicações mais diretas do modelo de circulação da seção canal do porto/ Largo do Canéu na distribuição do material em suspensão, por meio de correlação entre salinidades e teores de material em suspensão. Para todos os dados, obtivemos coeficientes de correlação de 0,72 em situação de preamar e de 0,44 em baixa-mar.

Procedemos a seguir à correlação entre esses dois fatores, para os três niveis amostrados $(T, M$, e $B)$. Obtivemos as seguintes correlações em preamar $T=0,20, M=0,30$ e $B=$ 0,43 ; em baixa-mar, os valores foram $T=0,62, M=0,49 \mathrm{e}$ $B=0,43$. Verificamos assim que a distribuição do material em suspensão não guarda relação direta com a estratificação do estuário.

Procedemos então a novas corręlações entre salinidade e teores de material em suspensão, desta vez abrangendo três setores do estuário: um próximo à foz, compreendendo as estações de 1 a 5 ; um intermediário, estaçōes de 6 a 9; e outro inferior, estações de 11 a 14. Desta feita obtivemos as correlações de jusante para montante de: $0,78,0,83$ e 0,83 , em preamar; e de 0,62, 0,77 e 0,30, em baixa-mar. Esses resultados mostram que a melhor correlação observada em preamar para todas as amostras se mantém. Adicionalmente, nota-se que a menor correlação global da baixa-mar decorre da maior dispersão do material em suspensão na região dos largos, coincidentemente com uma tendência à ho-
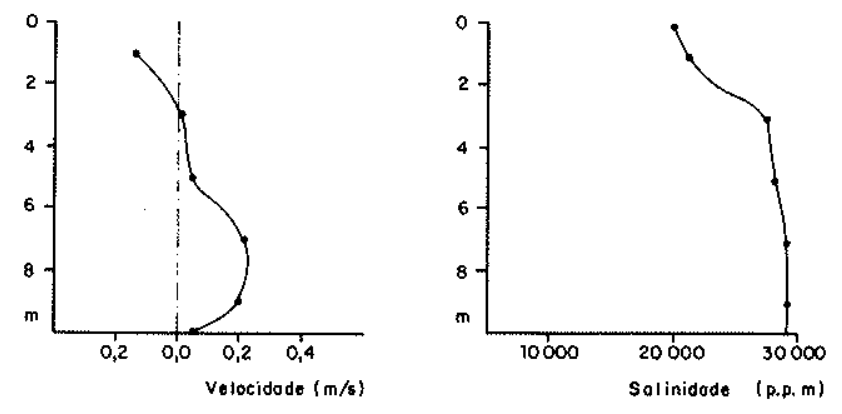

preamar

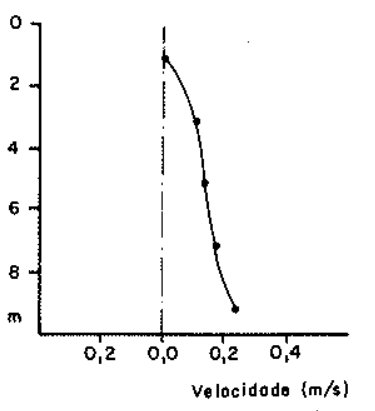

Th opós boixo-mor

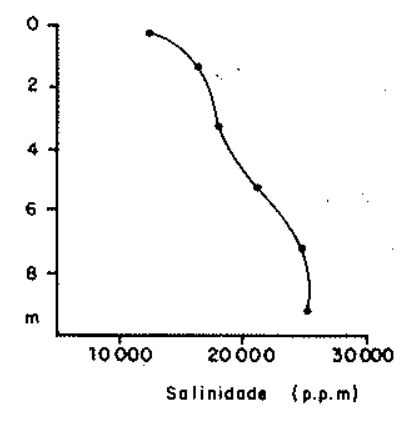

' $18 / 05 / 66)$

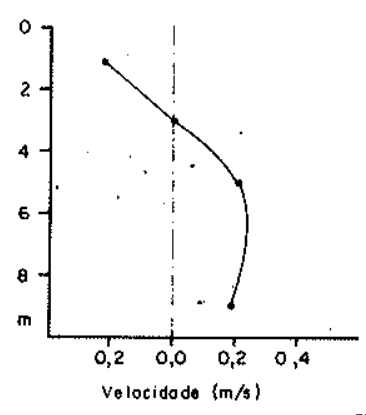

preonor

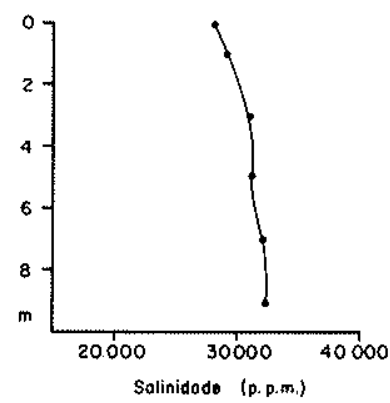

PONTA DA PRAIA $(19 / 05 / 66)$

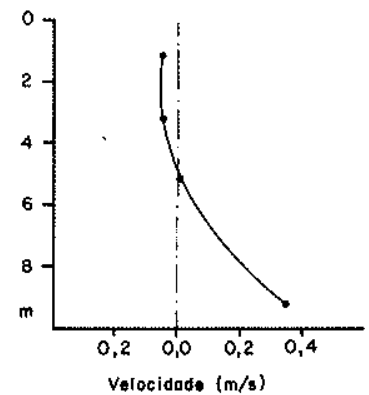

in apds boixo-mar

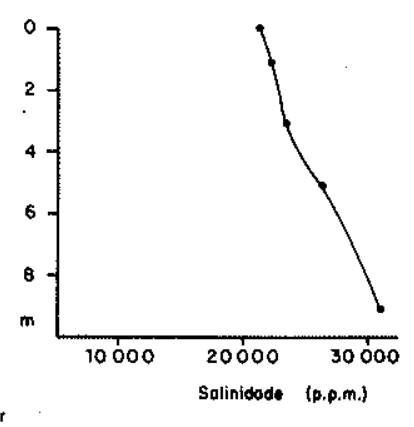

Figura 5 - Diagramas de velocidades de fluxo versus profundidades e salinidades versus profundidades 
mogeneização do gradiente de salinidades, conforme expuséramos anteriormente.

No conjunto, podemos concluir que a preamar o estuário apresenta relações mais nítidas quanto a velocidades de cor. rente, salinidade e material em suspensão. $\mathrm{Na}$ baixa-mar, embora com menor nitidez, há ainda boa definição de dois estratos e boa correlação destes com os teores de material em suspensão, ao longo do canal do porto; na região dos largos, a correlação é muito baixa.

Há portanto, uma certa mudança na dispersão dos sólidos em suspensão nessas duas situações, que pode ser associada à maior ou menor penetração de água marinha para $o$ interior do estuário, conforme se esteja em preamar ou em baixa-mar.

Nas condições investigadas, sob descarga fluvial de verão, a zona de turbidez máxima do canal do porto e largos estende-se entre as estações 1 e 9 (Fig. 4), sendo alimentada de preferência por sólidos em suspensão que acompanham a penetração đa água salgada proveniente da baía. Não há dados para estender essas considerações ao Canal de São Vicente.

Outro fator a ser considerado é o da agregação de partículas, sob o ponto de vista da zona de turbidez máxima e do modelo de circulação. Este último dado, no caso em questão, mostra considerável aporte de água marinha para o interior do estuário, à altura dos largos. Isto implica que, do ponto de vista eletrolítico, há condições de precipitação de flocos também nessa região.

Levando em conta, como já se notara anteriormente (EPUSP/DAEE 1966) que é nessa faixa dos largos que se estendem os manguezais, pode-se supor que os sólidos de origem fluvial ficam de preferência aí retidos por: 1) quebra de gradiente fluvial, perda de energia do meio transportador e conseqüente deposição das frações granulométricas mais grossas; 2) coagulação eletrolítica das frações finas; e 3) fixação do material assim depositado por efeito tanto físico (coesão, velocidades críticas de deposição e erosão) como biológico (crescimento de vegetação do mangue).

Entre a região do alto estuário e o canal do porto, nos largos, estende-se uma região caracterizada por teores de material em suspensão mais baixos que os da zona de turbi. dez máxima. Em decorrência, só na porção terminal do canal do porto voltam a haver condiçōes mais favoráveis à agregação de partículas, desta vez devido a aumentos locais de concentração de sólidos em suspensão, ná zona de turbidez máxima. Neste caso, pode ocorrer agregação pelo aumento do número de choques entre partículas, conforme mostraram Krone (1978) e Krank (1981).

CONCLUSÃo A investigação sedimentológica efetuada em curto prazo, sob mesmas condições de maré, permite determinar melhor o padrão de circulação estuarina. Neste sentido, pudemos estabelecer, no estuário santista, sob condições de verão e marés de sizígia, que o canal do porto e sua continuação pelos largos internos se aproximam do modelo de duas camadas com mistura vertical, e não da cunha salina, conforme se postulava previamente. Adicionalmente, o Canal de São Vicente exibe padrão próximo do vertical* mente homogêneo, com predomínio de circulação marinha, situação que começa a se modificar para uma incipiente estratificação em sua porção próxima aos largos.

\section{REFERÊNCIAS BIBLIOGRÁFICAS}

AZEVEDO, A. (Coord) - $1965-A$ baixada Santista: aspectos geográficos. São Paulo, EDUSP, 4v.

BOWDEN, K.F. - 1967 - Circulation and diffusion. In: LAUFF, G.H. ed. Estuaries. Washington, American Association for the Advancement of Science, p.15-36. (Publication, 83).

DAEE - 1974 - Dados fluviométricos coligidos a té 1970 na quinta zona hidrográfica, Bacia do Rio Ribeira e Iguape e Bacias Litorâneas. Boletim fluviométrico, São Paulo, (2): 1-391.

EPUSP/DAEE - 1966 - O estuário santista: pesquisa sobre o asso. reamento verificado na faixa portuária, para a Companhia Docas de Santos. São Paulo, DAEE, cap. 3., p. 14-101.

FULFARO, V.J. \& PONÇANO, W.L. - 1976 - Sedimentação atual do estuário e baía de Santos: um modelo geológico aplicado a projetos de expansão da zona portuária. In: CONG. BRAS. GEOL. ENG., 1, Rio de Janeiro, 1976. Anais..., Rio de Janeiro, ABGE, v. 2, p. 85-110.

KRANK, K. - 1981 - Particle matter grain-size characteristics and flocculation in a partially mixed estuary. Sedimentology, 28:107-114.

KRONE, R.B. - 1978 - Aggregation of suspended particles in estuaries. In: KJERFVE, B. ed. Estuarine transport processes. University of South Carolina, USA.

NIMER, E. - 1977 - Clima. In: INSTITUTO BRASILEIRO DE GEOGRAFIA E ESTATISTICA. Geografia do Brasil; região sudeste. Rio de Janeiro, v. 3, p. 51-90.

PONCANO, W.L. \& FÚLFARO, V.J. - 1976 - Sedimentação atual nas adjacências da Ponta de Itaipu e Baía de Santos: Implicaçoes na escollha de locais de lançamento de material dragado. In: CONG. BRAS. GEOL. DE ENG., 1, Rio de Janeiro, 1976. Anais..., Rio de Janeiro, ABGE. v. 2, p. 91-110.

MANUSCRITO Recebido em 06 de março de 1986 Revisão aceita em 05 de ju nho de 1986

Teorias não são meros exercícios de diletantismo científico ou veleidades a serem banidas. A adoção de uma teoria é passo indelével da investigação científica, como degrau da observação do conjunto, sistemática e persistente, na busca de um arranjo cöerente de conhecimentos. 